\title{
Documentary Effects on Medical Student Attitudes \& Skills Regarding Nutrition at the End of Life
}

\author{
Scott De La Cruz ${ }^{1}$, Francesca Nicosia ${ }^{2}$, Eva Aagaard ${ }^{1}$ \\ ${ }^{1}$ Department of General Internal Medicine, University of Colorado Denver, Denver, USA \\ ${ }^{2}$ Department of Anthropology, History and Social Medicine, University of \\ California San Francisco, San Francisco, USA \\ Email: scott.delacruz@ucdenver.edu
}

Received January $1^{\text {st }}, 2014$; February $1^{\text {st }}, 2014$; accepted February $8^{\text {th }}$, 2014

\begin{abstract}
Copyright $\odot 2014$ Scott De La Cruz et al. This is an open access article distributed under the Creative Commons Attribution License, which permits unrestricted use, distribution, and reproduction in any medium, provided the original work is properly cited. In accordance of the Creative Commons Attribution License all Copyrights (c) 2014 are reserved for SCIRP and the owner of the intellectual property Scott De La Cruz et al. All Copyright (C) 2014 are guarded by law and by SCIRP as a guardian.
\end{abstract}

\begin{abstract}
Medical trainees rarely have the opportunity to provide comprehensive end of life care or see the physical transformation of the dying process. Studies suggest that the use of film in medical education is an effective means of exposing students to aspects of medicine they might not otherwise receive. Dying Wish is a visual instrumental case study of a patient with end-stage cancer who chose to stop eating and drinking at the end of his life. In this randomized, controlled study, we assessed the impact of Dying Wish on medical students' attitudes, knowledge, and confidence in patient/family discussions surrounding nutrition at the end of life using student surveys and independently validated standardized patient assessments. By the middle of the first clinical year, about $58 \%$ of students witnessed and $38.6 \%$ actively participated in a discussion regarding nutrition at the end of life with a patient and/or their family. Although there was no significant difference in students' self-perceived knowledge or skills, a significantly higher percentage of students who viewed "Dying Wish" prior to standardized patient visits clearly explained the biological consequences of stopping eating and drinking compared to those who had not viewed the film. Students agreed that "Dying Wish" improved their knowledge of the physical effects of stopping eating and drinking and effectively introduced the ethical and psychosocial issues associated with nutrition at the end of life. Documentaries are considered by students to be effective teaching tools and "Dying Wish" represents a feasible way to deliver instruction regarding nutrition at the end of life. Visual depictions and documentary films that portray the natural courses of illnesses may prove to be helpful, efficient teaching tools and their role in the educational process for healthcare providers should continue to be studied.
\end{abstract}

Keywords: Medical Education; Documentary Film; Visual Instrumental Case Study; End of Life; Nutrition

\section{Introduction}

Understanding and identifying the signs and symptoms of death is an essential skill needed by all physicians to provide quality care and, as such, is an important component of medical students' competency in end of life care (Field \& Cassel, 1997; Gibbins, McCoubrie, Alexander, Kinzel, \& Forbes, 2009; Nelson, Angoff, \& Binder, 2000). Medical trainees rarely have the opportunity to provide comprehensive end of life care or see the physical transformation of the dying process (Gibbins, McCoubrie, Alexander, Kinzel, \& Forbes, 2009; Billings \& Block, 1997). This lack of exposure may result in medical trainees feeling underprepared and having difficulty educating patients and their families about what to expect at the end of life (Buss, Marx, \& Sulmasy, 1998; Fraser, Kutner, \& Pfeifer, 2001; Van der Riet, Good, Higgins, \& Sneesby, 2008; Gibbins, McCoubrie, \& Forbes, 2011).

Didactic sessions can be limited in their ability to convey complex aspects of care. Experiential approaches including standardized patients, role-play, and the humanities have been shown to be effective means of learning affective and skillsbased objectives (Block, Bernier, \& Crawley, 1998; Schmidt, Norton, \& Tolle, 1992; Serwint \& Simpson, 2002; Kahn, Sherer, Alper, Lazarus, Ledoux, Anderson, \& Szerlip, 2001). Early studies suggest that the use of film in medical education is an effective means of exposing students to aspects of medicine they might not otherwise receive (Self, DeWitt, \& Baldwin, 1990). Films can be used to educate, create self-reflection and generate discussion about the general emotional reactions of the viewer, diagnostic impressions, therapeutic and treatment considerations, and associations with one's own profession and personal life (Alexander \& Lenahan, 2005).

Dying Wish is a visual instrumental case study of Dr. Michael Miller, a retired surgeon with end-stage cancer who voluntarily chose to stop eating and drinking at the end of his life. The film documents Dr. Miller's decision-making process and raises the topics of bioethics, spirituality, patient autonomy, voluntary refusal of food and fluids (VRFF), as well as the physical and emotional aspects of stopping eating and drinking. The film allows the viewer to visualize the physical dying 
process and the physiology of stopping eating and drinking at the end of life.

In this study, we assessed the impact of Dying Wish on medical students' attitudes, knowledge, and confidence in patient/ family discussions surrounding nutrition at the end of life. In addition, we assessed the effect of the film on the likelihood that students would initiate a conversation about nutrition or VRFF and the adequacy of their description of the biological consequences of such a decision during a simulated patient encounter.

\section{Methods}

\section{Study Design}

This randomized, single-blinded, controlled trial took place at University of Colorado School of Medicine during a required one-week curriculum delivered near the mid-point of the third year of medical school. The overarching goal of the curriculum is to teach the fundamentals of end of life care and advanced communication skills. One hundred twenty-seven medical students answered questions about their knowledge, attitudes and self-confidence in discussing the topic of nutrition/hydration at the end of life via a computerized Likert scale survey at the start of the one-week curriculum. Three yes or no questions also assessed the students' prior personal and curriculum-associated experiences with nutrition at the end of life. Students were then randomized into 2 groups (Figure 1 ).

The intervention cohort $(n=64)$ viewed Dying Wish and then worked in pairs to lead a standardized patient (SP) encounter of a family meeting wherein the patient has late stage Alzheimer's disease and has been admitted for recurrent aspiration pneumonia. The family is being asked to address the issue of nutrition and hydration, among other end of life issues. The control cohort $(n=64)$ completed the same SP encounter in pairs without having viewed Dying Wish. Immediately following the SP encounter, students from both groups were asked again about their knowledge, attitudes and self-confidence regarding nutrition/hydration via a computerized survey.

SPs completed a computerized checklist that asked if the medical students: 1) initiated a conversation about nutrition at the end of life, 2) mentioned voluntary refusal of food and fluids as an option at the end of life, and 3) clearly explained the biological consequences of stopping eating and drinking at the end of life. The SPs were blinded to intervention or control group assignment status. The SPs' responses to the checklists were validated by a video review of 20 randomly selected encounters.

Finally, all students were asked about their level of agree-

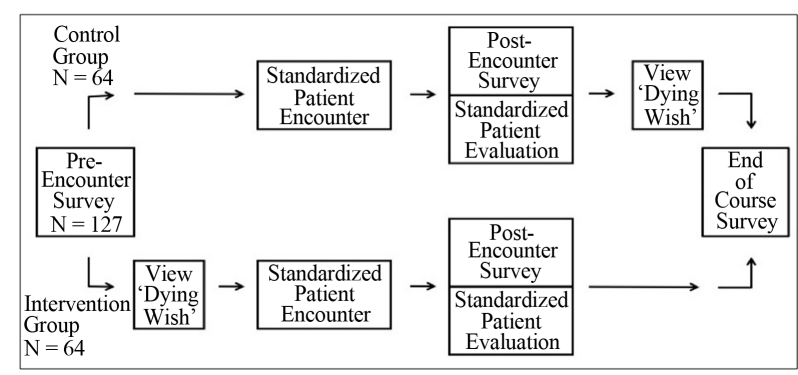

Figure 1.

Study design. ment regarding the usefulness of "Dying Wish" and documentary films in general for medical education as part of the course evaluation at the completion of the week of curriculum. A Likert-type scale was used to measure responses: $1=$ strongly disagree, 2 =disagree, 3 = agree, 4 = strongly agree.

\section{Statistical Methods}

Chi-square analysis was used to compare the control and intervention groups' responses to the pre-SP encounter survey and their performances on the SP checklist. McNemar's test was used to compare students' responses to the pre- and postSP encounter surveys within groups. The Wilcoxon signed rank test was used to compare the intervention and control groups' responses to the post-SP encounter survey. Descriptive analysis of the 4 point Likert-type scale survey administered at the end of the weeklong curriculum documented the perceived efficacy of the documentary film as a teaching tool.

\section{Results}

\section{Demographic Information}

One hundred and twenty-eight of the 147 students that graduated in the class of 2011 participated in the surveys. The discrepancy in the number of students reflects those who were absent or who joined the graduating class later from combined degree programs or other causes for delay in training. There were $48.3 \%$ female students, $10.2 \%$ ethnically diverse students and the age range at the time of graduation was 26 years 9 months to 39 years 11 months.

\section{Pre-Intervention Survey}

Of all the students surveyed, $58.2 \%$ (57.1\% of the control group and $59.4 \%$ of the intervention group) reported that they had witnessed a discussion regarding nutrition at the end of life with a patient and/or their family in their role as a medical student, while $38.6 \%$ (31.7\% of the control group and $45.3 \%$ of the intervention group) had actively participated in such a discussion with a patient and/or their family in their role as a medical student and $44.1 \%$ (44.7\% of the control group and $43.8 \%$ of the intervention group) had personal experience with decisions regarding nutrition at the end of life outside of their role as a medical student. There were no significant differences found between the control and intervention groups with regard to prior experiences with nutrition at the end of life.

A majority of students felt they had the knowledge $(62.5 \%$ control and $57.1 \%$ intervention) and skills (68.8\% control and $68.3 \%$ intervention) necessary to discuss the biological effects of stopping eating and drinking at the end of life. Fewer students felt they had the knowledge (56.3\% and $49.2 \%$, respectively) or skills (65.6\% and $68.3 \%$, respectively) to discuss the various nutrition options at the end of life. Most students in both groups felt that voluntary refusal of food and fluid at the end of life is both ethical and legal. There were no significant differences found between the control and intervention groups in self-perceived knowledge or skills on the pre-intervention survey.

\section{Post-Intervention Survey}

Both the control and intervention groups reported significant improvements in the knowledge and skills needed to lead a 
discussion with patients and their families regarding nutritional options and the biological effects of stopping eating and drinking at the end of life (Table 1).

In addition, both the control and intervention groups significantly improved with regards to their comfort level with discussing nutrition at the end of life. Neither group significantly changed its belief that voluntary refusal of food and fluids at the end of life is both legal and ethical.

\section{SP Evaluation of Student's Performance}

SPs did not note a significant difference between the control and intervention groups in the percentage of students that initiated conversations about nutrition nor those that mentioned voluntary refusal of food and fluids as an option (Table 2).

However, a significantly higher percentage of students in the intervention group clearly explained the biological consequences of stopping eating and drinking at the end of life (76\% vs. $48 \%, p=0.005)$.

\section{End of Curriculum Survey}

Students agreed that documentary films can be effective tools for teaching medical topics (mean Likert-type response was 3.3/4.0, SD 0.6). In addition, students agreed that "Dying Wish" improved their knowledge of the physical effects of stopping eating and drinking (mean Likert response 3.1/4.0, SD 0.7) and effectively introduced the ethical and psychosocial issues associated with nutrition at the end of life (mean Likert response 3.1 and 3.1/4.0, SD 0.7 and 0.6 respectively). Students were not concerned that "Dying Wish" was shown to manipulate their personal thinking regarding nutrition at the end of life (mean Likert response was 2.1, SD 0.8).

\section{Discussion}

This study describes mid-third year medical students' experiences, knowledge and attitudes regarding nutrition at the end of life and VRFF at one institution. By the middle of third year, just over $58 \%$ of students witnessed and $38.6 \%$ actively participated in a discussion regarding nutrition at the end of life with a patient and/or their family in their role as a medical student. Although watching Dying Wish did not improve students' self-perceived knowledge or skills compared to those who did not, a significantly higher percentage of students who viewed "Dying Wish" prior to their SP visits clearly explained the biological consequences of stopping eating and drinking compared to those who had not viewed the film. Students agreed that "Dying Wish" improved their knowledge of the physical effects of stopping eating and drinking and effectively introduced the ethical and psychosocial issues associated with nutrition at the end of life.

Medical trainees rarely have the opportunity to provide comprehensive end of life care or see the physical transformation of the dying process. This lack of exposure may result in medical trainees having difficulty educating patients and their families about what to expect (Van der Riet, Good, Higgins, \& Sneesby, 2008). In our study, although both the control and intervention groups reported significant improvements in the knowledge and skills needed to lead a discussion with patients and their families regarding nutritional options, SPs reported that students who had viewed Dying Wish were significantly more likely to clearly explain the biological consequences of stopping eating and drinking during the standardized patient encounter. This suggests that Dying Wish helped the students to translate their new knowledge and skills to actual behavior at least in the simulated environment.

Table 1.

Responses to pre- and post-SP encounter surveys.

\begin{tabular}{|c|c|c|c|c|c|c|c|}
\hline & \multicolumn{3}{|c|}{ Control Group $(n=64)$} & \multicolumn{3}{|c|}{ Intervention Group $(n=63)$} & \multirow[t]{2}{*}{ Comparison } \\
\hline & $\begin{array}{l}\text { Before SP } \\
\text { Encounter }\end{array}$ & $\begin{array}{l}\text { After SP } \\
\text { Encounter }\end{array}$ & & $\begin{array}{l}\text { Before SP } \\
\text { Encounter }\end{array}$ & $\begin{array}{l}\text { After SP } \\
\text { encounter }\end{array}$ & & \\
\hline & $\begin{array}{l}\text { \% answering } \\
\text { "yes" or "agree" }\end{array}$ & $\begin{array}{l}\text { \% answering } \\
\text { “yes” or “agree” }\end{array}$ & $\begin{array}{l}\text { \% change } \\
\text { ( } p \text {-value) }\end{array}$ & $\begin{array}{l}\text { \% answering } \\
\text { “yes” or "agree” }\end{array}$ & $\begin{array}{l}\text { \% answering } \\
\text { "yes" or "agree" }\end{array}$ & $\begin{array}{l}\text { \% change } \\
\text { ( } p \text {-value) }\end{array}$ & $\begin{array}{l}\text { Control vs. } \\
\text { Intervention } \\
p \text {-value }\end{array}$ \\
\hline $\begin{array}{l}\text { I have the knowledge I need to discuss the } \\
\text { biological effects of stopping eating and } \\
\text { drinking at the end of life. }\end{array}$ & $62.5 \%$ & $81.3 \%$ & $\begin{array}{l}+18.8 \% \\
(0.002)\end{array}$ & $57.1 \%$ & $82.5 \%$ & $\begin{array}{l}+25.4 \% \\
(0.000)\end{array}$ & 0.851 \\
\hline $\begin{array}{l}\text { I have the skills I need to discuss the biological } \\
\text { effects of stopping eating and drinking } \\
\text { at the end of life. }\end{array}$ & $68.8 \%$ & $84.4 \%$ & $\begin{array}{l}+15.6 \% \\
(0.004)\end{array}$ & $68.3 \%$ & $82.5 \%$ & $\begin{array}{l}+14.2 \% \\
(0.008)\end{array}$ & 0.952 \\
\hline $\begin{array}{l}\text { I have the knowledge I need to discuss the } \\
\text { various options for nutrition at the end of life. }\end{array}$ & $56.3 \%$ & $75.0 \%$ & $\begin{array}{l}+18.7 \% \\
(0.002)\end{array}$ & $49.2 \%$ & $63.5 \%$ & $\begin{array}{l}+14.3 \% \\
(0.008)\end{array}$ & 0.782 \\
\hline $\begin{array}{l}\text { I have the skills I need to discuss the various } \\
\text { for nutrition at the end of life }\end{array}$ & $65.6 \%$ & $84.4 \%$ & $\begin{array}{l}+18.8 \% \\
(0.002)\end{array}$ & $68.3 \%$ & $81.0 \%$ & $\begin{array}{l}+12.7 \% \\
(0.008)\end{array}$ & 0.754 \\
\hline $\begin{array}{l}\text { Based on my personal beliefs, VRFF at } \\
\text { the end of life is ethical. }\end{array}$ & $92.2 \%$ & $95.3 \%$ & $\begin{array}{l}+3.1 \% \\
(0.480)\end{array}$ & $93.7 \%$ & $88.9 \%$ & $\begin{array}{l}-4.8 \% \\
(0.248)\end{array}$ & 0.749 \\
\hline $\begin{array}{l}\text { Legally, a patient has the right to voluntarily } \\
\text { refuse food and fluids at the end of life. }\end{array}$ & $93.8 \%$ & $96.9 \%$ & $\begin{array}{l}+3.1 \% \\
(0.480)\end{array}$ & $87.3 \%$ & $98.4 \%$ & $\begin{array}{l}+11.1 \% \\
(0.023)\end{array}$ & 0.216 \\
\hline $\begin{array}{l}\text { I feel comfortable leading a discussion } \\
\text { about options for nutrition at the end of life. }\end{array}$ & $59.4 \%$ & $84.4 \%$ & $\begin{array}{l}+25.0 \% \\
(0.00)\end{array}$ & $61.9 \%$ & $87.3 \%$ & $\begin{array}{l}+25.4 \% \\
(0.000)\end{array}$ & 0.771 \\
\hline
\end{tabular}


Table 2.

SP evaluation of students’ performance.

\begin{tabular}{lccc}
\hline & \multicolumn{3}{c}{$\%$ of SPs responding “Yes” } \\
\hline \multicolumn{1}{c}{ SP Checklist Item } & Control & Intervention & $p$-value \\
\hline $\begin{array}{l}\text { Medical student initiated } \\
\text { conversation about nutrition }\end{array}$ & $59 \%$ & $62 \%$ & 0.715 \\
$\begin{array}{l}\text { Medical student } \\
\text { mentioned VRFF }\end{array}$ & $64 \%$ & $63 \%$ & 0.351 \\
$\begin{array}{l}\text { Medical student clearly explained the } \\
\text { biological consequences of starvation }\end{array}$ & $48 \%$ & $76 \%$ & 0.005 \\
\hline
\end{tabular}

The results of this study further supports the idea that films can be used as an adjunct in medical education to provide experiences that are hard to ensure consistently during clinical training. The students surveyed as part of this study agreed that documentary films can be effective tools for teaching and agreed that "Dying Wish" improved knowledge of the physical effects of stopping eating and drinking. The efficacy of "Dying Wish" is consistent with prior studies of humanities modalities as educational tools for end of life topics (Self, DeWitt, \& Baldwin, 1990; Lorenz, Steckart, \& Rosenfeld, 2004; Weber \& Silk, 2007; Kumagai, 2008).

There are some limitations to this study and its assessment. As the film was shown to students as part of a weeklong multimodal end of life curriculum, it is difficult to isolate the effects of the film on the changes in self-reported attitudes and knowledge. It is also unclear how evaluations and self-reported efficacy at this early point in medical students' careers will translate to ability in actual practice. Traditionally self-report has been an unreliable measure of clinical skill (Davis, Thomson, O’Brien, Freemantle, Wolf, Mazmanian, \& Taylor-Vaisey, 1999).

\section{Conclusion}

Although the self-reported knowledge and skills around counseling patients regarding nutrition and VRFF at the end of life were not significantly altered by viewing "Dying Wish", the film did affect students' ability to clearly explain the biological effects of stopping eating and drinking to SPs. This is likely due to the film's visual depiction of the process of stopping eating and drinking at the end of life. Documentaries and other humanities modalities are considered by students to be effective teaching tools and "Dying Wish" represents a feasible way to deliver instruction regarding VRFF and nutrition at the end of life. Visual depictions and documentary films that portray the natural courses of illnesses may prove to be helpful, efficient teaching tools and their role in the educational process for healthcare providers should continue to be studied.

\section{REFERENCES}

Alexander, M., Lenahan, P., \& Pavlov, A. (2005). Cinemeducation: A comprehensive guide to using film in medical education. Singapore: Radcliffe Publishing.
Billings, J. A., \& Block, S. (1997). Palliative care in undergraduate medical education: Status report and future directions. JAMA, 278, 733-738. http://dx.doi.org/10.1001/jama.1997.03550090057033

Block, S. D., Bernier, G. M., \& Crawley, L. M. (1998). Incorporating palliative care into primary care education. National Consensus Conference on Medical Education for Care Near the End-of-life. Journal of General Internal Medicine, 13, 768-773. http://dx.doi.org/10.1046/j.1525-1497.1998.00230.x

Buss, M. K., Marx, E. S., \& Sulmasy, D. P. (1998). The preparedness of students to discuss end-of-life issues with patients. Academic Medicine, 73, 418-422. http://dx.doi.org/10.1097/00001888-199804000-00015

Davis, D., Thomson O’Brien, M. A., Freemantle, N., Wolf, F., Mazmanian, P., \& Taylor-Vaisey, A. (1999). Impact of formal continuing medical education-Do conferences, workshops, rounds, and other traditional continuing education activities change physician behavior or health care outcomes? JAMA, 282, 867-874. http://dx.doi.org/10.1001/jama.282.9.867

Field, M. J., \& Cassel, C K. (1997). Approaching death: Improving care at the end of life. Washington DC: National Academy Press.

Fraser, H. C., Kutner, J. S., \& Pfeifer, M. P. (2001). Senior medical students' perceptions of the adequacy of education on end-of-life issues. Journal of Palliative Medicine, 4, 337-343. http://dx.doi.org/10.1089/109662101753123959

Gibbins, J., McCoubrie, R., Alexander, N., Kinzel, C., \& Forbes, K. (2009). Diagnosing dying in the acute hospital setting-Are we too late? Clinical Medicine, 9, 16-19.

http://dx.doi.org/10.7861/clinmedicine.9-2-116

Gibbins, J., McCourbrie, R., \& Forbes, K. (2011). Why are newly qualified doctors unprepared to care for patients at the end of life? Medical Education, 45, 389-399. http://dx.doi.org/10.1111/j.1365-2923.2010.03873.x

Kahn, M. J., Sherer, K., Alper, A. B., Lazarus, C., Ledoux, E., Anderson, D., \& Szerlip, H. (2001). Using standardized patients to teach end-of-life skills to clinical clerks. Journal of Cancer Education, 16, 163-165.

Kumagai, A. K. (2008). A conceptual framework for the use of illness narratives in medical education. Academic Medicine, 83, 653-658. http://dx.doi.org/10.1097/ACM.0b013e3181782e17

Lorenz, K. A., Steckart, M. J., \& Rosenfeld, K. E. (2004). End-of-life education using the dramatic arts: The Wit educational initiative. Academic Medicine, 79, 481-486. http://dx.doi.org/10.1097/00001888-200405000-00020

Nelson, W., Angoff, N., \& Binder, E. (2000). Goals and strategies for teaching death and dying in medical schools. Journal of Palliative Medicine, 3, 7-16. http://dx.doi.org/10.1089/jpm.2000.3.7

Schmidt, T. A., Norton, R. L., \& Tolle, S. W. (1992). Sudden death in the ED: Educating residents to compassionately inform families. The Journal of Emergency Medicine, 10, 643-647. http://dx.doi.org/10.1016/0736-4679(92)90155-M

Self, D., DeWitt, C., \& Baldwin, J. (1990). Teaching medical humanities through film discussions. Journal of Medical Humanities, 11, 2329. http://dx.doi.org/10.1007/BF01142236

Serwint, J. R., \& Simpson, D. E. (2002). The use of standardized patients in pediatric residency training in palliative care: Anatomy of a standardized patient case scenario. Journal of Palliative Medicine, 5, 146-153. http://dx.doi.org/10.1089/10966210252785123

Van der Riet, P., Good, P., Higgins, I., \& Sneesby, L. (2008). Palliative care professionals' perceptions of nutrition and hydration at the end of life. International Journal of Palliative Nursing, 14, 145-151.

Weber, C. M., \& Silk, H. (2007). Movies and medicine: An elective using film to reflect on the patient, family, and illness. Family Medicine, 39, 317-319. 